\title{
Dental students' preference and perception on intraoral scanning and impression making
}

\author{
Walter Yu-Hang Lam*, Ken Chung-Kan Mak², Ebrahim Maghami ${ }^{3}$ and Pedro Molinero-Mourelle ${ }^{4}$
}

\begin{abstract}
Background: To investigate the preference and perception on intraoral scanning and impression making among dental students.

Methods: Final-year dental students from the 2019 and 2020 cohorts were invited to complete an online questionnaire via Google-Form. Their preference on the intraoral-scanning/impression making techniques and their perception on these techniques including the ease of defect identification, ease of infection control, need of chairside support, ease to master the technique as a beginner, efficiency in their hands and ease to handle the scanner software (yes/no) were collected. The results were analysed using McNemar tests and binary logistic regression test. All tests were performed at significance level $a=0.05$.
\end{abstract}

Results: Ninety-seven students participated in this study with a response rate of $96.0 \%$. Eighty-one students $(83.5 \%)$ have tried intraoral scanning on peers. Fifty-three (54.6\%) students preferred intraoral-scanning and were categorized as Pro-scanning group. Forty-four (45.4\%) students either preferred impression-making $(n=21)$ or not sure $(n=23)$ were categorized as Others. More than half of students in both groups felt that intraoral-scanning is easier to identify defect, easier in infection control and require less chairside support. Higher proportion of students in the Pro-scanning group felt that intraoral-scanning requires less chairside support, easier to master as a beginner, more efficient in their hands and they can deal well with the scanner software than that in Others $(P<0.05)$. Regression shown that students preferred a technique that they perceived is more efficient $(P=0.000)$.

Conclusions: While intraoral scanning has perceived advantages, many students still prefer impression making that works more efficient to them.

Keywords: Education; Professional; Perception; Dental Impression Technique; Digital Technology; Education, Dental, Graduate; Graduate; Continuing

\footnotetext{
* Correspondence: retlaw@hku.hk

This is a full paper to an abstract presented in the 34th International

Association for Dental Research - South East Asia Scientific Meeting in

November 2020.

'Prosthodontics, Restorative Dental Sciences, Faculty of Dentistry, The

University of Hong Kong, 34 Hospital Road, Prince Philip Dental Hospital Sai

Ying Pun, Hong Kong SAR, China

Full list of author information is available at the end of the article
}

(C) The Author(s). 2021 Open Access This article is licensed under a Creative Commons Attribution 4.0 International License, which permits use, sharing, adaptation, distribution and reproduction in any medium or format, as long as you give appropriate credit to the original author(s) and the source, provide a link to the Creative Commons licence, and indicate if changes were made. The images or other third party material in this article are included in the article's Creative Commons licence, unless indicated otherwise in a credit line to the material. If material is not included in the article's Creative Commons licence and your intended use is not permitted by statutory regulation or exceeds the permitted use, you will need to obtain permission directly from the copyright holder. To view a copy of this licence, visit http://creativecommons.org/licenses/by/4.0/ The Creative Commons Public Domain Dedication waiver (http://creativecommons.org/publicdomain/zero/1.0/) applies to the data made available in this article, unless otherwise stated in a credit line to the data. 


\section{Background}

Digital technologies have been utilized to aid the disease diagnosis and management in dentistry. The use of intraoral scanning (IOS) for the Virtual Patient Models creation [1-4] and Computer-Aided Design/Manufacturing (CAD/CAM) of esthetic and high-strength all-ceramic restorations have been widely adopted in dental clinics [5, 6]. Improved patient comfort has been reported for IOS [7] and clinicians no longer need to pour the stone casts and wait for their setting [8]. Using the CAD/CAM workflow, the time required for dental restoration fabrications has been significantly reduced when compared to the conventional restorative work flow [9].

Despite the advantages of digital dentistry and CAD/ CAM workflow, there are still significant proportion of dentists who do not adopt the IOS. One of the reasons is there are still some clinical limitations with these IOS systems, for instance, intra-arch discrepancy with IOS could be significant, rendering it not recommended for full arch prostheses in general [10]. Moreover, the sulcus reflection in the edentulous patient may be distorted during the scanning process and hence rendering it unsuitable for the fabrication of complete dentures with adequate border seal [11]. Moreover, there was huge variation in the types of procedures indicated for IOS among dental schools that have adopted IOS teaching [15].

Apart from clinical limitations, there are large variation in the reasons and barriers to adopt the IOS in the dental practice [12]. Factors such as innovation perception, personal, practice and social backgrounds all contribute to the acceptance to IOS. Graduating dental students therefore provides a relatively homogenous population for us to investigate the technology adoption of IOS. Compared to conventional impressions, training in dental schools in general devote less time on IOS, possibly due to time or equipment constraints [13, 14]. However, dental students' acceptance in the intraoral scanning are expected to be highest, as they are more willing to learn new techniques in the dental school, and they should have minimum technical barrier in adopting digital equipment and software. Equipment cost is also not a consideration among dental students. It would be helpful to investigate student's preferences and perceptions in IOS and impression making, which is less commonly explored.

In dental education, better learning experience will be achieved by considering students' preference and perception when designing the dental curriculum [15-17]. However, students' preference of IOS and impression making have not been investigated in relation to their learning experience [18]. Moreover, while the students' preference or perception of IOS has been studied in dentistry [19-21], the combined survey of preference and perception allow more reliable assessments [22].
Therefore, the aim of the present study was to explore the preference and perception of students in IOS and impression making. The first null hypothesis was there is no difference in the perception of IOS and impression making among dental students who has different preferences. The second null hypothesis was there is no relationship between the preference and perception of IOS and impression making among dental students.

\section{Methods}

This cross-sectional study was conducted in the academic year of 2018/2019 and 2019/2020 by means of an online questionnaire in the Faculty of Dentistry, The University of Hong Kong. This study were performed in accordance with the Declaration of Helsinki and has been approved by the Institutional Review Board of The University of Hong Kong and Hospital Authority Hong Kong West Cluster, Hong Kong (UW 20-514).

\section{Design/participants}

The impression making was taught at the second-year of the sixth-year dental curriculum and was the mainstay clinical technique in patient management. As the dental teaching hospital, Prince Philip Dental Hospital, has been equipped with intraoral scanners, all final-year undergraduate dental students were required to attend to an intraoral scanning (IOS) course and were allowed to use IOS in patient management thereafter. The course content includes an introductory lecture by a faculty staff, a demonstration of scanning on a full dentate typodont model by product specialists from several scanner manufacturers (Trios 3, 3 Shape, Copenhagen, Denmark; iTero Element 5D, Align Technologies, California, United States; Medit i500, Medit Corp, Seoul, Korea; Primescan, Dentsply Sirona, Bensheim, Germany), followed by hands-on practice by students. If time permitted, there was a peer-practice on intraoral scanning.

After the course, students from two cohorts (Class of 2019 and 2020) were invited to complete an online questionnaire via Google Forms (Google Inc., California, United States). Written informed consents were obtained. The questionnaire includes the intraoral scanning or impression making preference and six questions regarding their perception on the clinical practicality of these techniques including the ease of defect identification, ease of infection control, need of chairside support, ease to master the technique as a beginner, efficiency in their hands and operating the scanner software (yes/no). The general meaning of "efficiency" was used in this study and there was no specific definition for this term. 


\section{Statistical analyses}

Students' preference and perception of intraoral scanning and impression making were collected in proportions. Their differences were non-parametric nominal and paired in nature, and were analysed by the $\mathrm{McNe}$ mer test. The relationship between preference (dependent variable) and perception (independent variables) of intraoral scanning and impression making was analysed by the binary logistic regression test. The level of significance was set at $\alpha=0.05$. Data were analysed using Statistical Product and Service Solution (SPSS) 27.0 (IBM Corp., New York, USA).

\section{Results}

Ninety-seven final-year undergraduate dental students participated in this study, with 48 out of 50 students from Class of 2019 and 49 out of 51 students from Class of 2020 . The response rate of this study was $96.0 \%$. The mean age of participated students were 23.1 and $60 \mathrm{stu}-$ dents $(61.9 \%)$ were female and 37 students were male (38.1\%). Eighty-one students $(83.5 \%)$ had clinical experience in using intraoral scanners during the peerpractice.

\section{Preference of the intraoral scanning and impression making}

Intraoral scanning was the preferred technique among more than half of participated students. Fifty-three students $(54.6 \%)$ preferred intraoral scanning, while 17 students $(17.5 \%)$ preferred conventional impression and 27 students $(27.8 \%)$ have no preference (Table 1$)$. They were categorized into Pro-scanning group $(\mathrm{n}=53)$ and Others $(n=44)$ respectively.

\section{Perception of the intraoral scanning and impression making}

Students' perception of intraoral scanning and impression making was presented in Table 2. More than half of participated students perceived that intraoral scanning were easier to identify a defect $(n=59,60.8 \%)$, easier in infection control ( $n=68,70.1 \%)$, less chairside support $(\mathrm{n}=83,85.6 \%)$, easier to master as a beginner $(n=66$, $68.0 \%)$, and more efficient in their hands $(n=51$, $52.6 \%)$. More than half of participated students

Table 1 Students' preferred technique $(n=97)$

\begin{tabular}{lc}
\hline & Number (\%) \\
\hline Pro-scanning group & $53(54.6 \%)$ \\
Prefer intraoral scanning & \\
Others & $17(17.5 \%)$ \\
Prefer impression making & $27(27.8 \%)$ \\
No preference & \\
\hline
\end{tabular}

perceived that they could operate the scanner software well ( $\mathrm{n}=55,56.7 \%)$.

Higher proportion of students in the Pro-scanning group perceived that intraoral scanning requires less chairside support $(P=0.03)$, easier to master as a beginner $(P=0.03)$, and more efficient in their hands $(P=$ $0.000)$ than students in Others. Higher proportion of students in the Pro-scanning group perceived that they dealt well with the scanner software $(P=0.01)$ than students in Others.

Relationship between the preference and perception of intraoral scanning and impression making

Binary logistic regression showed that students preferred a technique that they perceived to be more efficient in their hands $(P=0.000)$ (Table 3$)$.

\section{Discussion}

More than half $(54.6 \%)$ of all participated final-year undergraduate students preferred intraoral scanning (IOS). This finding is similar to a previous study which found $63.9 \%$ of students felt positive to IOS [23]. In the Pro-scanning group, there was a significantly higher proportion of students who perceived IOS requires less chairside support, easier to master as a beginner, and more efficient than the students in the Others $(P<0.05)$, the first null hypothesis was therefore rejected. Fifty-five $(56.7 \%)$ students in this study did not have difficulty in operating the scanner software which is in agreement with a previous study which found $60.2 \%$ of students considered scanning process as manageable [23]. Considering these findings, the dental curriculum should incorporate more IOS component such as relevant background knowledge and clinical competence training.

In the binary logistic regression model, students' preferred technique was linked to a technique that is perceived to be more efficient by them $(P=0.000)$. The second null hypothesis was therefore rejected. In the Oxford learner's dictionaries, "efficient" means "doing something in a good, careful and complete way with no waste of time, money or energy" [24]. Lee et al. defined time and number of retakes/rescans as efficiency [25]. Among other clinical advantages, IOS is more efficient than impression making as it does not require time for mixing and setting of impression material, disinfecting the impression, and pouring of the stone models [2628]. Areas that are less than ideal can be easily removed to allow recapture or simply re-scanning alone [29]. On the other hand, critical errors in the impressions (e.g. bubbles along preparation margins, unclear margins) will render the whole impression useless and the whole impression will need to be made again [30]. Such repeated attempts of impressions are common [31, 32], especially 
Table 2 Perception of intraoral scanning and impression making by students

\begin{tabular}{|c|c|c|c|c|}
\hline Perception & Intraoral scanning & Impression making $^{\mathrm{a}}$ & Not sure ${ }^{\mathrm{a}}$ & $p$-value \\
\hline \multicolumn{5}{|c|}{ Easier to identify a defect } \\
\hline Overall & 59 & 28 & 10 & \\
\hline \multirow[t]{2}{*}{ Pro-scanning group } & 34 & 15 & 4 & \\
\hline & & & & 0.46 \\
\hline Others & 25 & 13 & 6 & \\
\hline \multicolumn{5}{|c|}{ Easier in infection control } \\
\hline Overall & 68 & 19 & 10 & \\
\hline \multirow[t]{2}{*}{ Pro-scanning group } & 39 & 10 & 4 & \\
\hline & & & & 0.41 \\
\hline Others & 29 & 9 & 6 & \\
\hline \multicolumn{5}{|l|}{ Less chairside support } \\
\hline Overall & 83 & 9 & 5 & \\
\hline \multirow[t]{2}{*}{ Pro-scanning group } & 45 & 8 & 0 & \\
\hline & & & & 0.03 \\
\hline Others & 38 & 1 & 5 & \\
\hline \multicolumn{5}{|c|}{ Easier to master as a beginner } \\
\hline Overall & 66 & 21 & 10 & \\
\hline \multirow[t]{2}{*}{ Pro-scanning group } & 41 & 10 & 2 & \\
\hline & & & & 0.03 \\
\hline Others & 25 & 11 & 8 & \\
\hline \multicolumn{5}{|l|}{ More efficient } \\
\hline Overall & 51 & 31 & 15 & \\
\hline \multirow[t]{2}{*}{ Pro-scanning group } & 41 & 9 & 3 & \\
\hline & & & & 0.000 \\
\hline Others & 10 & 22 & 12 & \\
\hline Perception & Yes & $\mathrm{No}^{\mathrm{a}}$ & Not sure $e^{a}$ & \\
\hline \multicolumn{5}{|c|}{ Dealt well with the scanner software } \\
\hline Overall & 55 & 16 & 25 & \\
\hline \multirow[t]{2}{*}{ Pro-scanning group } & 36 & 6 & 10 & \\
\hline & & & & 0.01 \\
\hline Others & 19 & 10 & 15 & \\
\hline
\end{tabular}

*McNemar tests

atem "Impression making" and "No" were analysed with "Not sure" in the McNemar tests

Table 3 Binary logistic regression of the preference (Proscanning group versus Others) and the perception of intraoral scanning and impression making

\begin{tabular}{llllr}
\hline & B & S.E. & P-value & Exp (B) \\
\hline Easier to identify a defect & -0.185 & 0.537 & 0.731 & 0.831 \\
Easier in infection control & -0.236 & 0.588 & 0.688 & 0.791 \\
Less chairside support & -2.155 & 1.218 & 0.077 & 0.116 \\
Easier to master as a beginner & -0.235 & 0.617 & 0.703 & 0.791 \\
More efficient & 2.615 & 0.618 & $\mathbf{0 . 0 0 0}$ & 13.663 \\
Dealt well with the scanner software & -0.652 & 0.522 & 0.212 & 0.521 \\
Constant & 2.452 & 2.822 & 0.385 & 11.610 \\
\hline
\end{tabular}

among dental students who are still in the learning stage. With the aid of intraoral scanners, errors in impression can be identified easily under the magnified view and any further corrections can be made much more efficiently, saving student's chairside time [19, 23, 33, 34].

In the present study around one-fifth $(17.5 \%)$ of students still settled upon impression making and around one-fourth of students $(27.8 \%)$ did not have any preferred technique. We also found that the particular technique perception that works more efficient might affect the preference of students, therefore, with more practise and clinical exposure of IOS, more students might prefer IOS. This has implication that more IOS courses, integrated in 
the postgraduate degrees or as short continuous professional development modules, should be provided to the dental professionals. On the other hands, as was mentioned in the introduction, the full arch scanning error and the sulcus capture failure mean that the teaching of impression making and related knowledge should not be abandoned at this level. With these perceived advantages, many undergraduate students still like to choose impression making and realized that impression making is more efficient in their hands. Nevertheless further studies are needed in order to determine the factors that affect students' perceived technique that is more efficient to them.

Intraoral scanners, as with any impression technique, processes a learning curve $[35,36]$. Some areas in the mouth might not be easy to capture with intraoral scanners such as the distal surfaces of the last tooth in an arch as well as the proximal surfaces near to a bounded saddle. It is difficult for beginners to move the tip of intraoral scanners around while following the scanner's signals based on recognizing previously captured surfaces [37]. The IOS and impression making probably require different competence skills [25, 34, 38]. Students in this study were exposed to various intraoral scanners, differences in the system and the scanning protocols may result in variations in success of impression making $[37,39,40]$. However, most of the students able to operate the scanners well during the hands-on and peerpractice. The user-friendliness of the newer generation of intraoral scanners might be the key factor for students' preference and their final assessment as well.

Some limitations of this study include the lack of clinical experience of students in intraoral scanning for a fair comparison. The lack of a real patient practice should be considered since a clinical scenario could provide additional information considering the limitations and complications of impression making in dental students at the beginning of their clinical practice. Students' only experience with intraoral scanner might be the peer-practice that is straightforward because their colleagues usually have a full set of dentition. Participated students in this study were young and were expected to more adaptive to new technology such as IOS. The result of this study may be extrapolated to dentists who have more clinical experience and should be more efficient in impression making, therefore higher proportion of them is expected to prefer impression making than IOS. Further studies are needed to investigate the preference and perception of dentists in IOS and impression making.

\section{Conclusions}

Intraoral scanning (IOS) is favoured among final-year undergraduate dental students. While intraoral scanning has perceived advantages, many students still prefer impression making that works more efficient to them. More IOS courses, integrated in the postgraduate degrees or as short continuous professional development modules, should be provided to the dental professionals. Meanwhile, dental schools should prepare students to be competent in both techniques to handle different clinical situations.

\section{Abbreviations}

IOS: Intraoral Scanning; CAD/CAM: Computer-Aided Design/Manufacturing

\section{Acknowledgements}

Authors would like to express gratitude to the undergraduate dental students Mr. Chan Kin Wah, Sheldon and Mr. Chan Hau Chun, Samuel for their assistance in collecting questionnaire.

\section{Authors' contributions}

WL involved in the conception, design of the work; KM involved in the acquisition, analysis, and interpretation of data; WL, EM and PM have drafted the work or substantively revised it. All authors read and approved the final manuscript.

\section{Funding}

Nil.

\section{Availability of data and materials}

The dataset used and/or analysed is this study are available from the corresponding author on reasonable request.

\section{Declarations}

Ethics approval and consent to participate

The study has been approved by the Institutional Review Board of The University of Hong Kong and Hospital Authority Hong Kong West Cluster, Hong Kong (UW 20-514). Written informed consents were obtained from participants.

Consent for publication

Not applicable.

\section{Competing interests}

The authors declare that they have no competing interests.

\section{Author details}

${ }^{1}$ Prosthodontics, Restorative Dental Sciences, Faculty of Dentistry, The University of Hong Kong, 34 Hospital Road, Prince Philip Dental Hospital Sai Ying Pun, Hong Kong SAR, China. 'Dental Service, Department of Health, 21/ F, Wu Chung House, 213 Queen's Road East, Hong Kong SAR, Hong Kong, China. ${ }^{3}$ Department of Mechanical Engineering and Mechanics, Drexel University, 3141 Chestnut Street, PA 19104 Philadelphia, USA. ${ }^{4}$ Department of Reconstructive Dentistry and Gerodontology, School of Dental Medicine, University of Bern, 6 Hochschulstrasse, CHE 3012 Bern, Switzerland.

Received: 8 June 2021 Accepted: 22 August 2021

Published online: 22 September 2021

\section{References}

1. Joda T, Gallucci GO: The virtual patient in dental medicine. Clin Oral Implants Res 2015, 26(6):725-726

2. Lam WY, Hsung RT, Choi WW, Luk HW, Pow EH: A 2-part facebow for CADCAM dentistry. J Prosthet Dent 2016, 116(6):843-847.

3. Lam WY, Hsung RT, Choi WW, Luk HW, Cheng LY, Pow EH: A clinical technique for virtual articulator mounting with natural head position by using calibrated stereophotogrammetry. J Prosthet Dent 2018, 119(6):902908.

4. Lam WY, Hsung RT, Cheng LY, Pow EH: Mapping intraoral photographs on virtual teeth model. J Dent 2018, 79:107-110. 
5. Miyazaki T, Hotta Y, Kunii J, Kuriyama S, Tamaki Y: A review of dental CAD/ CAM: current status and future perspectives from 20 years of experience. Dent Mater J 2009, 28(1):44-56.

6. Maghami E, Homaei E, Farhangdoost K, Pow EHN, Matinlinna JP, Tsoi $\mathrm{JK}-\mathrm{H}$ : Effect of preparation design for all-ceramic restoration on maxillary premolar: a 3D finite element study. J Prosthodont Res 2018, 62(4):436-442

7. Joda T, Brägger U: Patient-centered outcomes comparing digital and conventional implant impression procedures: a randomized crossover trial. Clin Oral Implants Res 2016, 27(12):e185-e189.

8. Grünheid T, McCarthy SD, Larson BE: Clinical use of a direct chairside oral scanner: an assessment of accuracy, time, and patient acceptance. Am J Orthod Dentofacial Orthop 2014, 146(5):673-682

9. Joda T, Brägger U. Time-efficiency analysis comparing digital and conventional workflows for implant crowns: A prospective clinical crossover trial. Int J Oral Maxillofac Implants. 2015;30(5).

10. Patzelt SB, Emmanouilidi A, Stampf S, Strub JR, Att W: Accuracy of full-arch scans using intraoral scanners. Clin Oral Invest 2014, 18(6):1687-1694.

11. Baba NZ. The Fabrication of Digital Complete Dentures. Treating the Complete Denture Patient 2020:263-270.

12. van der Zande MM, Gorter RC, Wismeijer D: Dental practitioners and a digital future: an initial exploration of barriers and incentives to adopting digital technologies. Br Dent J 2013, 215(11):E21-E21.

13. Chatham C, Spencer M, Wood D, Johnson A: The introduction of digital dental technology into BDS curricula. Br Dent J 2014, 217(11):639-642.

14. Brownstein SA, Murad A, Hunt RJ: Implementation of new technologies in US dental school curricula. J Dent Educ 2015, 79(3):259-264.

15. Murphy RJ, Gray SA, Straja SR, Bogert MC: Student learning preferences and teaching implications. J Dent Educ 2004, 68(8):859-866.

16. Jessee SA, O'Neill PN, Dosch RO: Matching student personality types and learning preferences to teaching methodologies. J Dent Educ 2006, 70(6): 644-651.

17. Turkyilmaz I, Hariri NH, Jahangiri L: Student's perception of the impact of elearning on dental education. J Contemp Dent Pract 2019, 20(5):616-621.

18. Schott TC, Arsalan R, Weimer K: Students' perspectives on the use of digital versus conventional dental impression techniques in orthodontics. BMC Med Educ 2019, 19(1):1-6.

19. Ahmed KE, Wang T, Li KY, Luk WK, Burrow MF: Performance and perception of dental students using three intraoral CAD/CAM scanners for full-arch scanning. J Prosthodont Res 2019, 63(2):167-172.

20. Marti A, Harris B, Metz M, Morton D, Scarfe W, Metz C, Lin WS: Comparison of digital scanning and polyvinyl siloxane impression techniques by dental students: instructional efficiency and attitudes towards technology. Eur J Dent Educ 2017, 21(3):200-205.

21. Al Hamad KQ: Learning curve of intraoral scanning by prosthodontic residents. J Prosthet Dent 2020, 123(2):277-283.

22. McCullough J, Best R: Conjoint measurement: temporal stability and structural reliability. J Mark Res 1979, 16(1):26-31

23. Wegner K, Michel K, Seelbach PH, Wöstmann B: A questionnaire on the use of digital denture impressions in a preclinical setting. Int J Comput Dent 2017, 20(2):177-192

24. Oxford learner's dictionaries.

25. Lee SJ, Gallucci GO: Digital vs. conventional implant impressions: efficiency outcomes. Clin Oral Implants Res 2013, 24(1):111-115.

26. Patzelt SB, Emmanouilidi A, Stampf S, Strub JR, Att W: Accuracy of full-arch scans using intraoral scanners. Clin Oral Investig 2014, 18(6):1687-1694.

27. Richert R, Goujat A, Venet L, Viguie G, Viennot S, Robinson P, Farges J-C, Fages M, Ducret M: Intraoral scanner technologies: a review to make a successful impression. J Healthc Eng 2017, 2017.

28. Ting-shu S, Jian S: Intraoral digital impression technique: a review. J Prosthodont 2015, 24(4):313-321.

29. Ferrari M, Keeling A, Mandelli F, Giudice GL, Garcia-Godoy F, Joda T: The ability of marginal detection using different intraoral scanning systems: A pilot randomized controlled trial. Am J Dent 2018, 31(5): 272-276.

30. Davidowitz G, Kotick PG: The use of CAD/CAM in dentistry. Dental Clinics 2011, 55(3):559-570.

31. e Silva JSA, Erdelt K, Edelhoff D, Araújo É, Stimmelmayr M, Vieira LCC, Güth J-F: Marginal and internal fit of four-unit zirconia fixed dental prostheses based on digital and conventional impression techniques. Clin Oral Investig 2014, 18(2):515-523.
32. Seelbach P, Brueckel C, Wöstmann B: Accuracy of digital and conventiona impression techniques and workflow. Clin Oral Investig 2013, 17(7):17591764.

33. Ahmed KE, Peres KG, Peres MA, Evans JL, Quaranta A, Burrow MF: Operators matter-An assessment of the expectations, perceptions, and performance of dentists, postgraduate students, and dental prosthetist students using intraoral scanning. J Dent 2021, 105:103572.

34. Joda T, Lenherr P, Dedem P, Kovaltschuk I, Bragger U, Zitzmann NU: Time efficiency, difficulty, and operator's preference comparing digital and conventional implant impressions: a randomized controlled trial. Clin Oral Implants Res 2017, 28(10):1318-1323.

35. Róth I, Czigola A, Joós-Kovács GL, Dalos M, Hermann P, Borbély J: Learning curve of digital intraoral scanning-an in vivo study. BMC Oral Health 2020, 20(1):1-7.

36. Zitzmann NU, Matthisson L, Ohla H, Joda T: Digital undergraduate education in dentistry: a systematic review. Int J Environ Res Public Health 2020, 17(9):3269.

37. Zarone F, Ruggiero G, Ferrari M, Mangano F, Joda T, Sorrentino R: Comparison of different intraoral scanning techniques on the completely edentulous maxilla: An in vitro 3-dimensional comparative analysis. J Prosthet Dent 2020, 124(6):762. e761-762. e768.

38. Bilir $\mathrm{H}$, Ayguzen C: Comparison of digital and conventional impression methods by preclinical students: Efficiency and future expectations. J Int Soc Prev Community Dent 2020, 10(4):402.

39. Rhee Y-K, Huh Y-H, Cho L-R, Park C-J: Comparison of intraoral scanning and conventional impression techniques using 3-dimensional superimposition. J Adv Prosthodont 2015, 7(6):460

40. Chiu A, Chen Y-W, Hayashi J, Sadr A: Accuracy of CAD/CAM digital impressions with different intraoral scanner parameters. Sensors 2020, 20(4): 1157

\section{Publisher's Note}

Springer Nature remains neutral with regard to jurisdictional claims in published maps and institutional affiliations.
Ready to submit your research? Choose BMC and benefit from:

- fast, convenient online submission

- thorough peer review by experienced researchers in your field

- rapid publication on acceptance

- support for research data, including large and complex data types

- gold Open Access which fosters wider collaboration and increased citations

- maximum visibility for your research: over $100 \mathrm{M}$ website views per year

At BMC, research is always in progress.

Learn more biomedcentral.com/submissions 